\title{
Effects of beclomethasone/formoterol fixed combination on lung hyperinflation and dyspnea in COPD patients
}

This article was published in the following Dove Press journal:

International Journal of COPD

30 September 2011

Number of times this article has been viewed

\author{
Panagiota Tzani' \\ Ernesto Crisafulli2 \\ Gabriele Nicolini ${ }^{3}$ \\ Marina Aiello' \\ Alfredo Chetta' \\ Enrico Maria Clini² \\ Dario Olivieri' \\ 'Department of Clinical Sciences, \\ University of Parma, Parma, \\ Italy; ${ }^{2}$ Department of Oncology \\ Haematology and Pulmonary Diseases, \\ University of Modena and Ospedale \\ Villa Pineta, Pavullo, Modena, Italy; \\ ${ }^{3}$ Medical Affairs Department, Chiesi \\ Farmaceutici SpA, Parma, Italy
}

Correspondence: G Nicolini Medical Affairs Department,

Chiesi Farmaceutici SpA, via Palermo

26/A-43 I00 Parma, Italy

$\mathrm{Tel}+39052127956$ I

Fax +390521279592

Email g.nicolini@chiesigroup.com
Background: Chronic obstructive pulmonary disease (COPD) is a common disease characterized by airflow obstruction and lung hyperinflation leading to dyspnea and exercise capacity limitation.

Objectives: The present study was designed to evaluate whether an extra-fine combination of beclomethasone and formoterol (BDP/F) was effective in reducing air trapping in COPD patients with hyperinflation. Fluticasone salmeterol (FP/S) combination treatment was the active control.

Methods: COPD patients with forced expiratory volume in one second $<65 \%$ and plethysmographic functional residual capacity $\geq 120 \%$ of predicted were randomized to a doubleblind, double-dummy, 12-week, parallel group, treatment with either BDP/F 400/24 $\mu$ g/day or FP/S 500/100 $\mu \mathrm{g} /$ day. Lung volumes were measured with full body plethysmography, and dyspnea was measured with transition dyspnea index.

Results: Eighteen patients were evaluable for intention to treat. A significant reduction in air trapping and clinically meaningful improvement in transition dyspnea index total score was detected in the BDP/F group but not in the FP/S group. Functional residual capacity, residual volume (RV) and total lung capacity significantly improved from baseline in the BDP/F group only. With regard to group comparison, a significantly greater reduction in RV was observed with $\mathrm{BDP} / \mathrm{F}$ versus $\mathrm{FP} / \mathrm{S}$.

Conclusion: BDP/F extra-fine combination is effective in reducing air trapping and dyspnea in COPD patients with lung hyperinflation.

Keywords: small airways, chronic obstructive pulmonary disease, airflow obstruction

\section{Introduction}

Chronic obstructive pulmonary disease (COPD) is a common disease with airflow limitation due to both small airways obstruction and parenchimal damage. ${ }^{1}$ Although the measure of airflow limitation is a key point for the diagnosis and staging of COPD, static lung volumes have a better correlation with individually perceived symptoms and exercise capacity. ${ }^{2,3}$ Moreover, parameters of hyperinflation show better correlation with patient-centered health outcomes than does forced expiratory volume in one second $\left(\mathrm{FEV}_{1}\right) .^{2}$ Indeed, the presence of hyperinflation in COPD, at rest or during exercise, can cause worsening of respiratory muscle function and gas exchange, and/or increase in work of breathing. ${ }^{4}$ Nonetheless, the degree of lung hyperinflation remains often undetected in the absence of detailed physiologic analysis. ${ }^{4}$ Daily physical activity of COPD patients is mainly associated with dynamic hyperinflation, regardless of severity classification ${ }^{5}$ and relief of exertional dyspnea following pharmacologic 
therapy shows good correlation with a reduction in dynamic hyperinflation. ${ }^{6}$ Hence, targeting hyperinflation can make a difference to the patient.

In COPD patients, an inhaled glucocorticosteroid (ICS) combined with a long-acting $\beta_{2}$-agonist (LABA) has an important role in clinical exacerbations of disease, ${ }^{7}$ improving lung function and health status. ${ }^{1}$ This combination therapy is of particular relevance in patients with frequent exacerbations associated with a rapid decline in lung function and increased mortality. ${ }^{8,9}$

The fixed combination of beclomethasone (BDP) $100 \mu \mathrm{g}$ plus formoterol (F) $6 \mu \mathrm{g}$ in a solution formulation is now available in a hydrofluoralkane pressurized metered-dose inhaler (pMDI). This formulation delivers the two drugs with an extra-fine particle size, which results in high lung deposition with the potential to target inflammation and bronchoconstriction, throughout the entire bronchial tree. ${ }^{10}$

The aim of this study was to assess the role of beclomethasone and formoterol (BDP/F) extra-fine versus fluticasone/ salmeterol (FP/S) combination on lung function parameters and dyspnea in COPD patients with hyperinflation.

\section{Methods}

This trial was conducted in two Italian units of respiratory medicine (Parma and Pavullo n/F-Modena).

\section{Patients}

Patients were included if aged 40-70 years, current or past smokers ( $>20$ pack years) with a confirmed diagnosis of COPD according to GOLD (Global initiative for chronic Obstructive Lung Disease) guidelines, ${ }^{1}$ a post-bronchodilator $\mathrm{FEV}_{1}<65 \%$, plethysmographic functional residual capacity (FRC) $\geq 120 \%$ of the predicted normal values, and an increase from baseline in post-bronchodilator $\mathrm{FEV}_{1}$ value of at least 5\% (but less than 12\%). Exclusion criteria included: asthma or positive response to the reversibility test $\left(\mathrm{FEV}_{1}\right.$ increase $\geq 12 \%$ and $200 \mathrm{~mL}$ after $400 \mu \mathrm{g}$ salbutamol); COPD exacerbations and/or symptomatic infection of the airways in the previous 4 weeks requiring antibiotic therapy and or oral corticosteroid; history of clinically severe cardiovascular diseases, diabetes mellitus, and impaired hepatic and/or renal function; use of long-term oxygen therapy and patients undergoing a rehabilitation program. Moreover, patients treated with a higher daily dose of LABAs or ICS/LABA combination than that used in the study were excluded.

The trial was approved by the Ethics Review Board at each institution, and conducted in accordance with the Declaration of Helsinki and Good Clinical Practice Guidelines. All patients gave written informed consent.

\section{Study design}

This was a double-blind, double dummy, randomized, parallel group study. During a 2-week run-in period, all previous medications with the exception of short-acting salbutamol for symptom relief were withdrawn and COPD patients were randomly assigned to a 12-week double-blind treatment period with either BDP/F 100/6 $\mu \mathrm{g}$ two inhalations twice daily or FP/S 250/50 $\mu \mathrm{g}$ one inhalation twice daily. No other bronchodilator, inhaled or systemic corticosteroid, or different combinations of these were permitted during the study.

To ensure the double-blind design, each patient was given a pMDI and a Diskus ${ }^{\circledR}$ (GlaxoSmithKline, London, UK) dry-powder inhaler (DPI), with either active drug or placebo (double dummy), in accordance with the randomization list. Inhalers containing drug or placebo were identical in shape and color. Randomization was in balanced-block design using a computerized list.

Morning dose started with two inhalations from the pMDI followed by one inhalation from the Diskus DPI, with a 30-second interval between inhalations; the same procedure was followed for the evening dose. Administration was performed according to the inhaler instruction leaflets provided by the sponsor. A total of five clinic visits were performed at screening, randomization, and after 4, 8, and 12 weeks of treatment. At each visit, the morning dose was administered onsite at the hospital clinics under the investigator's supervision to ensure that the inhalation technique used by the patients was correct.

\section{Measurements}

Whole-body plethysmography was measured in accordance with a standard procedure ${ }^{11}$ at each visit, at least 12 hours following the previous evening dose, 8 hours after the last administration of short-acting bronchodilators, before study drug intake (pre-dose) and 30 minutes after drug administration (post-dose). Diffusion lung capacity for carbon monoxide was measured at each visit before drug administration. At the second visit, baseline dyspnea index (BDI) was recorded prior to the first administration of study medication to assess chronic activity-related dyspnea, whereas change in dyspnea over time was evaluated by the transition dyspnea index (TDI) prior to dosing at subsequent visits. ${ }^{12}$ To measure the endurance time (ET), in seconds, an incremental cardiopulmonary exercise test 
was also performed with cycle ergometer at the second visit, and constant-load tests were performed at $75 \%$ of the maximal work rate, as previously described, ${ }^{13}$ from the second visit onwards either pre-dose or 1 hour post dosing.

\section{Statistics}

Data are expressed as mean \pm standard error of the mean (SEM), unless otherwise specified. Due to the explorative nature of the study and the lack of data with BDP/F in COPD, no formal sample size calculation was performed. The analysis of covariance, with treatment and center as factors and baseline value as a linear covariate, was applied. The values measured in the randomization visit before study drug intake (pre-dose) were considered for baseline values. The adjusted means for the two groups at each visit and the adjusted treatment difference between groups at each visit were recorded. All analyses were performed with SAS ${ }^{\circledR}$ System (SAS Institute Inc, Cary, NC), version 9.1.3, Service Pack 4. Statistical significance was set at 0.05 two tailed, and all analyses were performed on the intention-to-treat population (ITT). Imputation of missing data was completed following last observation carried forward method for post-baseline data.

\section{Results}

Twenty patients entered the run-in period between 2006 and 2009, eighteen (15 males, age range 57-72 years, body mass index range $22.7-30.9 \mathrm{~kg} / \mathrm{m}^{2}$ ) were randomized, and 14 completed the study (Figure 1). During the run-in period, one patient was lost to follow-up and one was not compliant to study protocol and was not randomized. All randomized patients were treated and evaluated for ITT. Patient compliance to the scheduled doses of study drugs was $95 \%$ in both groups. Baseline lung function data of BDP/F and FP/S patient groups are presented in Table 1. Median (range) Medical Research Council and BDI scores were 2 (2-5) and 2.5 (2-5), and 8 (3-9) and 7 (3-9), in the BDP/F and FP/S groups, respectively. Groups were well balanced at baseline, and no difference between groups was detected in clinical functional and anthropometric parameters.

All parameters related to air trapping showed an improvement in pre-dose measurements, although not statistically significant, with BDP/F treatment but not with FP/S (Table 2). In post-dose measurements FRC, residual volume (RV) and total lung capacity (TLC) significantly improved from baseline to week 12 in the $\mathrm{BDP} / \mathrm{F}$ group

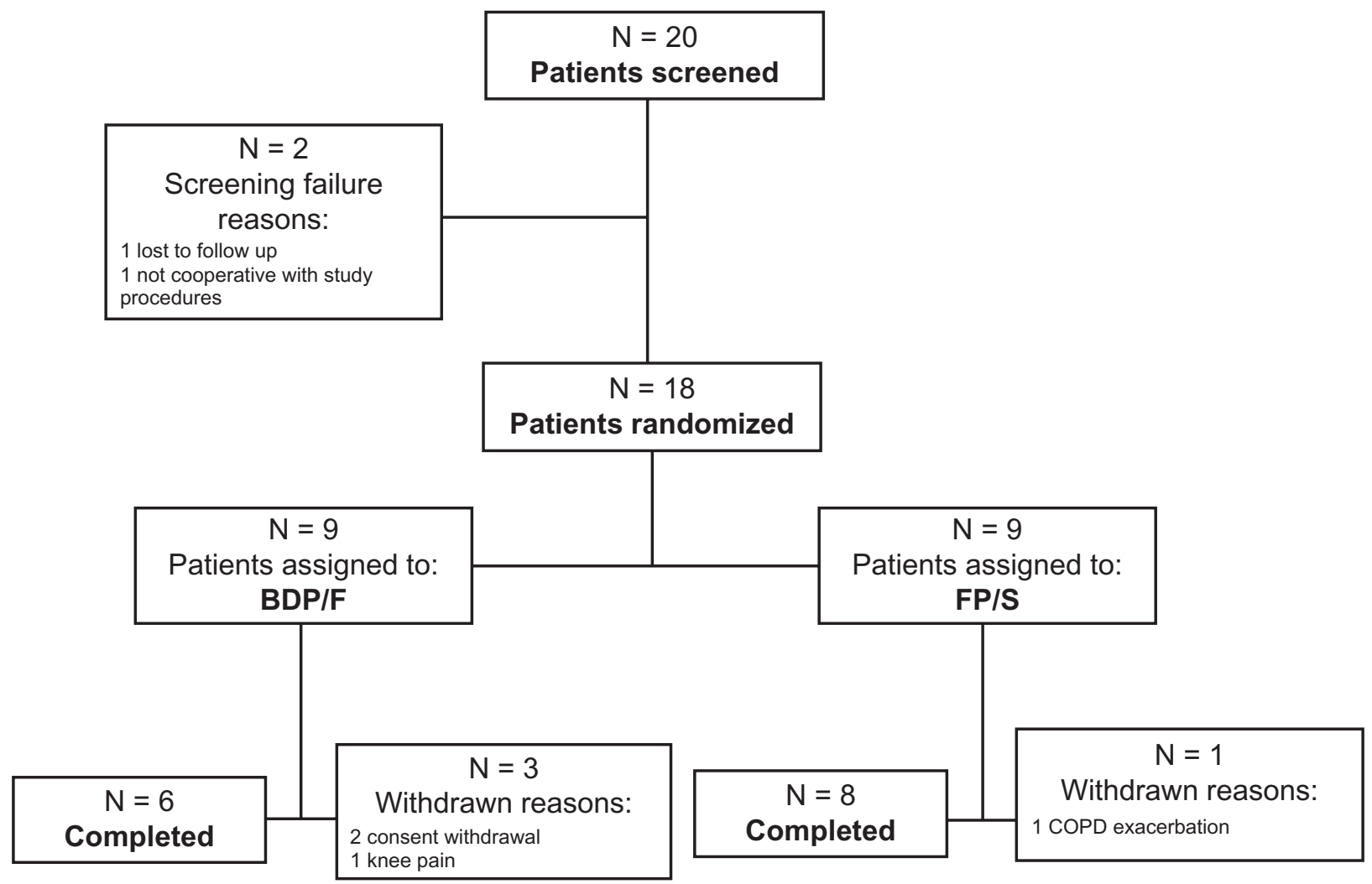

Figure I A flowchart representing patient flow.

Abbreviations: BDP/F, beclomethasone dipropionate/formoterol; FP/S, fluticasone propionate/salmeterol. 
Table I Baseline lung function data of the patients

\begin{tabular}{lcc}
\hline Parameter & $\begin{array}{c}\text { BDP/F } \\
(\mathbf{n}=\mathbf{9})\end{array}$ & $\begin{array}{l}\text { FP/S } \\
(\mathbf{n}=\mathbf{9})\end{array}$ \\
\hline FEV $_{1}, \mathrm{~L}$ & $1.27 \pm 0.16$ & $1.07 \pm 0.1 \mathrm{I}$ \\
FEV $_{1}, \%$ predicted & $45.1 \pm 5.0$ & $40.0 \pm 3.0$ \\
FVC, L & $2.80 \pm 0.3 \mathrm{I}$ & $2.42 \pm 0.27$ \\
FVC, \% predicted & $77 \pm 7$ & $72 \pm 6$ \\
FEV,/FVC, \% & $45 \pm 3$ & $45 \pm 3$ \\
FRC, L & $5.90 \pm 0.75$ & $5.84 \pm 0.38$ \\
FRC, \% predicted & $173.0 \pm 21.0$ & $186.3 \pm 10.0$ \\
RV, L & $4.73 \pm 0.76$ & $4.82 \pm 0.28$ \\
RV, \% predicted & $201.4 \pm 34.0$ & $224.5 \pm 13.0$ \\
TLC, L & $7.90 \pm 0.79$ & $7.59 \pm 0.49$ \\
TLC, \% predicted & $125.1 \pm 10.0$ & $131.4 \pm 7.0$ \\
RV/TLC, \% & $58.22 \pm 4.69$ & $64.00 \pm 2.29$ \\
FRC/TLC, \% & $73.65 \pm 2.68$ & $76.92 \pm 1.33$ \\
DLCO, mL/mmHg/min & $11.80 \pm 3.06$ & $11.66 \pm 1.64$ \\
\hline
\end{tabular}

Notes: Data are mean \pm standard error of the mean, measured in the randomization visit before study drug intake (pre-dose). No significant difference between groups was found in any parameter.

Abbreviations: BDP/F, beclomethasone dipropionate/formoterol; FP/S, fluticasone propionate/salmeterol; BMI, body mass index; $\mathrm{FEV}_{\text {, }}$, forced expiratory volume in one second; FVC, forced vital capacity; FRC, functional residual capacity; RV, residual volume; TLC, total lung capacity; DLCO, diffusion lung capacity for carbon monoxide; DLCO/VA, diffusion lung capacity for carbon monoxide corrected for alveolar volume.

only (Table 3 and Figure 2). Similarly, a trend towards improvement in forced vital capacity $(\mathrm{FVC})(P=0.064)$, FRC/TLC $(P=0.059)$, and RV/TLC $(P=0.062)$ was detected in the BDP/F group but not in the FP/S group (Table 3 and Figure 2). With regard to group comparison, a significantly greater reduction in RV was observed with $\mathrm{BDP} / \mathrm{F}$ versus FP/S (Table 3 and Figures 2 and 3 ).

A significant improvement in functional impairment TDI mean (SEM) score from baseline of $0.40(0.17)$ in the $\mathrm{BDP} / \mathrm{F}$ group $(P=0.033)$ and of $0.37(0.17)$ in the $\mathrm{FP} / \mathrm{S}$

Table 2 Body plethysmography lung volumes (pre-dose)

\begin{tabular}{lccll}
\hline Parameter & \multicolumn{1}{l}{$\begin{array}{l}\text { BDP/F } \\
(\mathbf{n}=\mathbf{9})\end{array}$} & \multicolumn{1}{l}{ FP/S } \\
& $(\mathbf{n}=\mathbf{9})$ & Difference & P-value \\
\hline IRV, L & $0.10 \pm 0.17$ & $-0.20 \pm 0.24$ & 0.31 & 0.338 \\
ERV, L & $-0.08 \pm 0.13$ & $0.01 \pm 0.13$ & -0.09 & 0.646 \\
RV, L & $-0.28 \pm 0.23$ & $0.19 \pm 0.23$ & -0.47 & 0.189 \\
TLC, L & $-0.29 \pm 0.21$ & $0.10 \pm 0.21$ & -0.38 & 0.231 \\
FRC, L & $-0.31 \pm 0.25$ & $0.23 \pm 0.25$ & -0.54 & 0.156 \\
FVC, L & $0.22 \pm 0.20$ & $0.02 \pm 0.20$ & 0.23 & 0.429 \\
IVC, L & $0.01 \pm 0.17$ & $-0.10 \pm 0.17$ & 0.11 & 0.679 \\
RV/TLC, \% & $-0.38 \pm 2.17$ & $1.83 \pm 2.17$ & -2.21 & 0.495 \\
FRC/TLC, \% & $-1.62 \pm 1.73$ & $2.49 \pm 1.73$ & -4.12 & 0.127 \\
\hline
\end{tabular}

Note: Data are adjusted mean \pm standard error of the mean; changes from baseline to the last visit before study drug intake (pre-dose).

Abbreviations: BDP/F, beclomethasone dipropionate/formoterol; FP/S, fluticasone propionate/salmeterol; IRV, inspiratory reserve volume; ERV, expiratory reserve volume; RV, residual volume; TLC, total lung capacity; FRC, functional residual capacity; FVC, forced vital capacity; IVC, inspiratory vital capacity.
Table 3 Body plethysmography lung volumes (post-dose)

\begin{tabular}{|c|c|c|c|c|}
\hline Parameter & $\begin{array}{l}\text { BDP/F } \\
(n=9)\end{array}$ & $\begin{array}{l}\text { FP/S } \\
(n=9)\end{array}$ & Difference & $P$-value \\
\hline IRV, L & $0.42 \pm 0.26$ & $-0.01 \pm 0.36$ & 0.43 & 0.372 \\
\hline ERV, L & $-0.05 \pm 0.10$ & $-0.02 \pm 0.10$ & -0.03 & 0.862 \\
\hline $\mathrm{RV}, \mathrm{L}$ & $-0.77 \pm 0.29 *$ & $0.14 \pm 0.29$ & -0.91 & 0.049 \\
\hline TLC, L & $-0.57 \pm 0.26^{*}$ & $0.20 \pm 0.26$ & -0.78 & 0.063 \\
\hline FRC, L & $-0.75 \pm 0.32 *$ & $0.23 \pm 0.32$ & -0.95 & 0.062 \\
\hline FVC, L & $0.31 \pm 0.15$ & $0.11 \pm 0.15$ & 0.20 & 0.395 \\
\hline IVC, L & $0.20 \pm 0.13$ & $0.06 \pm 0.13$ & 0.14 & 0.479 \\
\hline RV/TLC, \% & $-4.76 \pm 2.35$ & $0.65 \pm 2.35$ & -5.40 & 0.137 \\
\hline FRC/TLC, \% & $-4.62 \pm 2.25$ & $1.28 \pm 2.25$ & -5.90 & 0.096 \\
\hline
\end{tabular}

group $(P=0.046)$ was detected. A significant improvement in magnitude of task of $0.33(0.13)$ in the $\mathrm{BDP} / \mathrm{F}$ group $(P=0.024)$ was shown, whereas the change in the FP/S group was of $0.22(0.13)$ and was not significant $(P=0.110)$. No significant change was detected in magnitude of effort, which showed a change from baseline of $0.38(0.22)$ in the $\mathrm{BDP} / \mathrm{F}$ group $(P=0.122)$ and of $0.29(0.22)$ in the $\mathrm{FP} / \mathrm{S}$ group $(P=0.222)$. The TDI total score showed a significant and clinically relevant improvement from baseline of 1.144 $(0.46)$ in the BDP/F group $(P=0.026)$ but not in the FP/S group, for which the change was $0.86(0.46)(P=0.083)$ (Figure 4).

The mean \pm SEM adjusted values of pre-dose and post-dose ET at end of treatment were not statistically different in the BDP/F group (477.2 \pm 71.8 seconds and $513.6 \pm 79.2$ seconds), compared with the FP/S group (398.9 \pm 71.8 seconds and $475.6 \pm 79.2$ seconds).

Six adverse events were reported in five patients (three in the FP/S group and two in the BDP/F group). All these adverse events were considered not related to the study drugs and mild in severity apart from a COPD exacerbation in the FP/S group that was considered moderate and led to study discontinuation. Vital signs (blood pressure and heart rate) did not show clinically relevant changes over time in either group.

\section{Discussion}

This is the first study comparing the effects of two different ICS/LABA combinations on lung hyperinflation and dyspnea in COPD. The two groups were well balanced in baseline characteristics including smoking habits, diffusion lung capacity, spirometry, and lung volumes. The FP/S combination was selected as active comparator instead of 


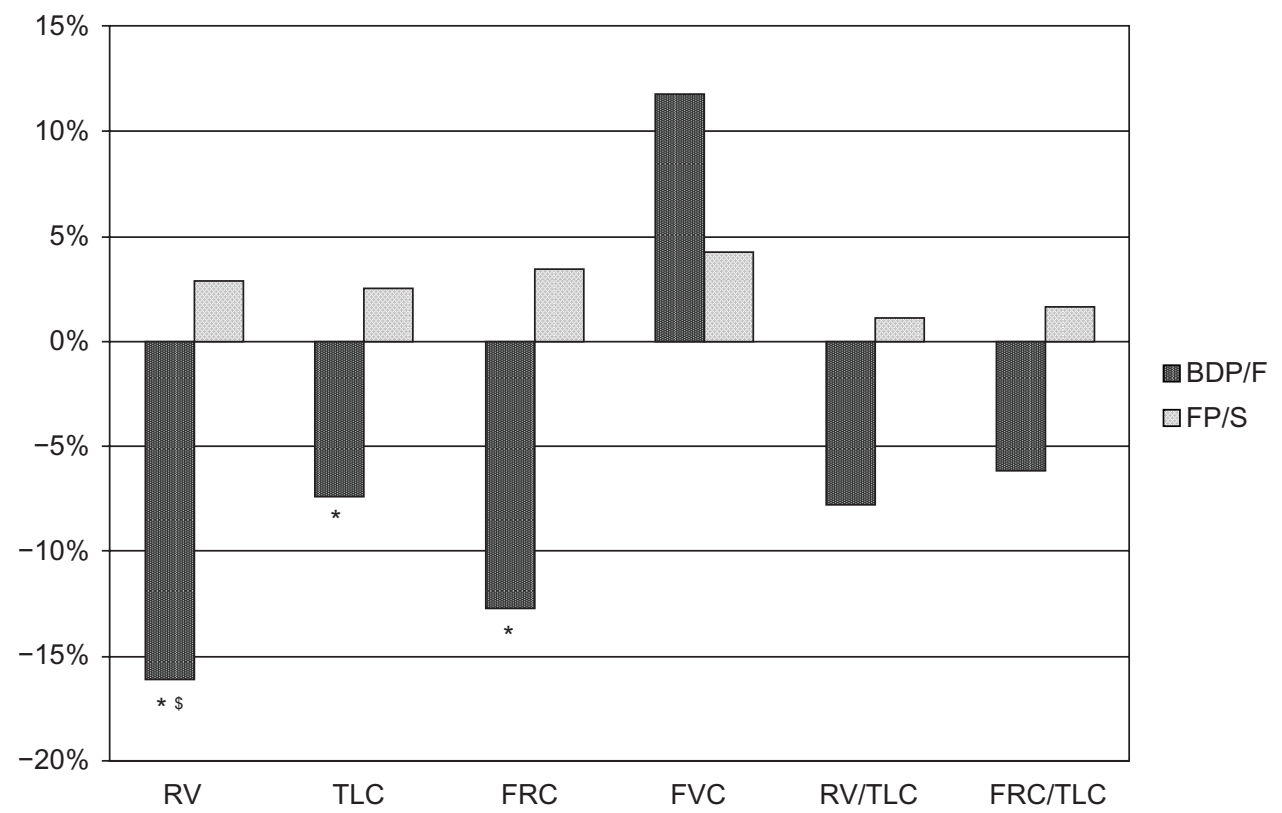

Figure 2 Percentage changes from baseline in lung function parameters measured after drug intake (post-dose) in the last visit. Notes: *Denotes $P<0.05$ versus baseline; ${ }^{\circledR}$ denotes $P<0.05$ versus FP/S.

Abbreviations: FRC, functional residual capacity; TLC, total lung capacity; FVC, forced vital capacity; RV, residual volume; BDP/F, beclomethasone dipropionate/formoterol; $\mathrm{FP} / \mathrm{S}$, fluticasone propionate/salmeterol.

placebo for ethical reasons and to provide clinically relevant information as this is one of the most used drugs for COPD patients in clinical practice.

The main findings of this study are that BDP/F improves lung function parameters related to air trapping and dyspnea in COPD patients. Body plethysmography measurements showed significantly improved FRC, TLC, and RV in $\mathrm{BDP} / \mathrm{F}$-treated patients, with a significantly greater reduction in RV compared with FP/S. These findings on reduction of $\mathrm{RV}$ and FRC are important determinants of improvement of dyspnea in COPD. ${ }^{14}$ Since this is the first data provided with BDP/F combination on lung hyperinflation, we can assume that the extra-fine formulation of $\mathrm{BDP} / \mathrm{F}$ is likely to

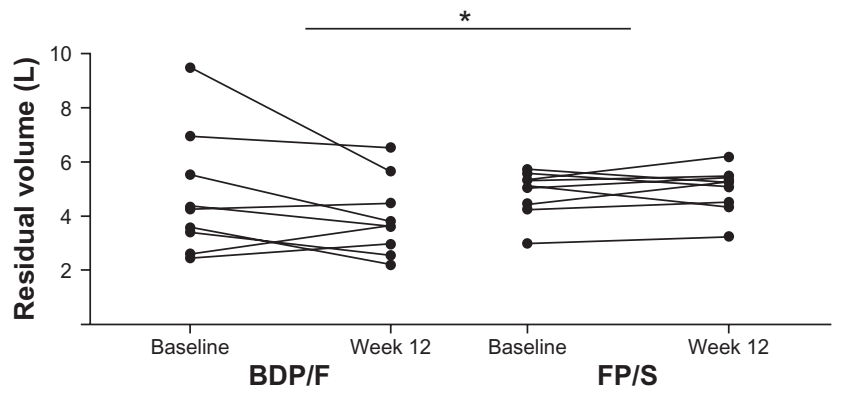

Figure 3 Individual patient changes from baseline to study end (post-dose) in residual volume.

Note: *Denotes $P<0.05$ between groups.

Abbreviations: BDP/F, beclomethasone dipropionate/formoterol; FP/S, fluticasone propionate/salmeterol. be one of the reasons for this effect, as the small particles delivered easily reach the small airways, with a uniform anti-inflammatory and bronchodilating effect. Indeed, peripheral airways obstruction is known to cause progressive "air trapping" during expiration, worsening of perceived dyspnea, and limitation of exercise capacity in COPD patients. ${ }^{1}$

The greater efficacy of BDP/F compared with $\mathrm{FP} / \mathrm{S}$ in reducing air trapping as observed in this study is in agreement with previous data. In asthmatics treated with the same daily doses of the same combinations, Papi and colleagues, in a randomized controlled trial, showed a significant increase in $\mathrm{FVC}$ with $\mathrm{BDP} / \mathrm{F}$ when compared with FP/S. ${ }^{15}$ Moreover, Scichilone et al showed a reduction in closing capacity consistent with a reduction in air trapping with $\mathrm{BDP} / \mathrm{F}$ but not with $\mathrm{FP} / \mathrm{S} .{ }^{16} \mathrm{~A}$ recently published large randomized controlled study showed a comparable efficacy of BDP/F extra-fine combination and budesonide/formoterol (BUD/F) combination in COPD patients. ${ }^{17} \mathrm{BDP} / \mathrm{F}$ treatment for 48 weeks improved pulmonary function and reduced symptoms compared with formoterol, improved the walking distance measured with the 6-minute walking test, improved quality of life, and was safe and well tolerated. Moreover, no significant difference was detected in any outcome between BDP/F extra-fine combination and $\mathrm{BUD} / \mathrm{F}$ combination. It is noteworthy that a significant improvement in FVC was detected in 


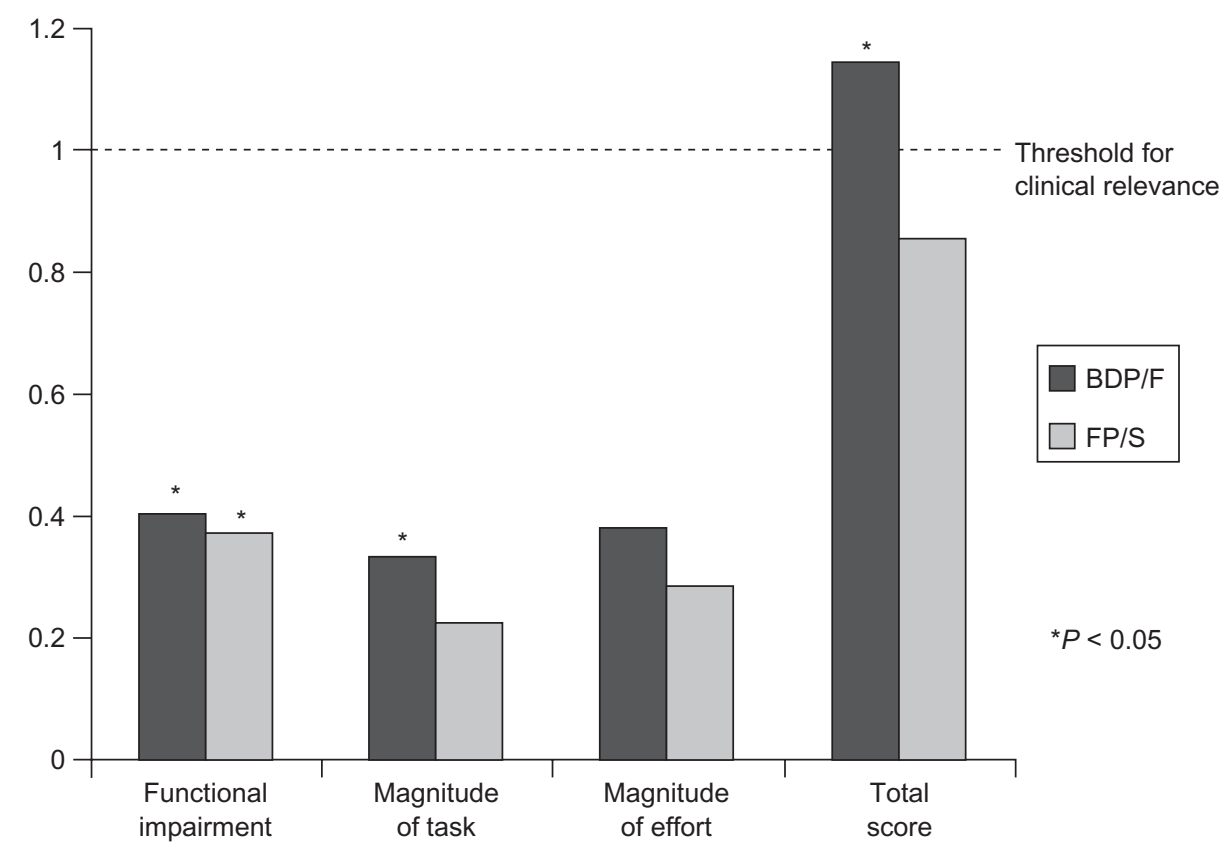

Figure 4 Transition dyspnea index score.

Note: *Denotes $P<0.05$ versus baseline.

Abbreviations: BDP/F, beclomethasone dipropionate/formoterol; FP/S, fluticasone propionate/salmeterol.

COPD patients treated with $\mathrm{BDP} / \mathrm{F}$ and not in those treated with BUD/F or F alone. ${ }^{17}$

As regards other lung function parameters measured in the present study, a trend towards improvement was shown in the $\mathrm{BDP} / \mathrm{F}$ group in FVC, FRC/TLC, and RV/TLC, and a trend for difference between groups was detected in FRC and TLC favoring BDP/F. Nonetheless, the number of patients was not enough to draw definitive conclusions on the different effects of the two investigated combinations on lung hyperinflation. Indeed, the inclusion criteria of high FRC, as a sign of resting hyperinflation, limited the potential for recruitment.

Interestingly, the present study demonstrates that BDP/F reduced TDI-dyspnea in terms of functional impairment, magnitude of task, and total score, whereas FP/S improved only functional impairment. Moreover, the increase in TDI total score with $\mathrm{BDP} / \mathrm{F}$ was greater than 1 unit, a change that is considered clinically relevant. ${ }^{18}$

The results of this study were achieved with a lower daily dose of corticosteroid in BDP/F extra-fine combination (400 $\mu \mathrm{g})$ compared with FP/S $(500 \mu \mathrm{g})$, due to the extra-fine formulation resulting in a greater efficacy per microgram of steroid, in agreement with previous studies. ${ }^{16,19,20}$ The use of a combination with a low corticosteroid dose can be of particular relevance in COPD patients as side effects of ICS are dose-dependent, with an increased risk of pneumonia recently highlighted in a study with high-dose $\mathrm{FP} / \mathrm{S}^{21}$

It could be argued that the greater efficacy of $\mathrm{BDP} / \mathrm{F}$ observed in the present study could be related to the characteristics of $\mathrm{F}$ and $\mathrm{S}$ in terms of onset of action. Actually, the improvements in air trapping related parameters were more evident in post-dose measurements, even if the trend for a greater effect with $\mathrm{BDP} / \mathrm{F}$ than with $\mathrm{FP} / \mathrm{S}$ is numerically evident even in pre-dose measurements. Therefore, a contribution of the bronchodilator component of each combination to the effect on lung function is likely, and we cannot exclude that this contributes to the between-group differences detected. Anyway, it has been shown that both $\mathrm{F}$ and $\mathrm{S}$ reach a maximum increase in $\mathrm{FEV}_{1}$ and IC in COPD patients 30 minutes after dosing, with no further improvement at 60 and 120 minutes thereafter, ${ }^{22}$ thus making it unlikely that the major reason for the differences is the onset of action of the two LABAs. Nevertheless, it has been shown in human small airways that formoterol has a higher intrinsic efficacy in reversing the carbachol-induced contraction as compared with salmeterol. ${ }^{23}$ This could support the explanation of a greater efficacy due to pharmacological activity on small airways of the extra-fine $\mathrm{BDP} / \mathrm{F}$ combination. It is noteworthy that the differences in favor of BDP/F in dyspnea improvements were detected in predose evaluation of dyspnea with the TDI score, thus suggesting that the difference between groups was evident even when the effect of the LABA was not present. We do not have all the data to conclude that the greater effect on air trapping of the $\mathrm{BDP} / \mathrm{F}$ combination is due to formoterol, to BDP, or to the extra-fine formulation reaching the small airways.

In conclusion, this study shows the efficacy on lung air trapping and perceived dyspnea of extra-fine $\mathrm{BDP} / \mathrm{F}$ 
combination - when compared with FP/S - in COPD patients. An improvement on patients' daily performance with this combination drug could therefore be assumed. Larger studies will confirm the precise role of $\mathrm{BDP} / \mathrm{F}$ and its potential advantages as compared with the other available treatments in the long-term management of COPD patients.

\section{Note}

This study was registered in the Italian Registry for Clinical Trials. ${ }^{24}$ The registration number is: 2005-005857-23.

\section{Disclosure}

The study was sponsored by Chiesi Farmaceutici SpA, Parma, Italy. PT and MA have no conflict of interest to declare. EC has undertaken research funded by Boehringer-Ingelheim, Chiesi Farmaceutici, Novartis, and Nycomed. GN is an employee of Chiesi Farmaceutici. AC and DO have undertaken research funded by Boehringer-Ingelheim, Chiesi Farmaceutici, GlaxoSmithKline, Novartis, and Nycomed. EMC has undertaken research funded by Boehringer-Ingelheim, Italy, Medical Research Product, and Medinet.

\section{References}

1. GOLD Report Executive Summary. Global Strategy for Diagnosis, Management, and Prevention of COPD. December 2010. In: GOLD - Global Initiative for Chronic Obstructive Lung Disease home page (http://www. goldcopd.org/guidelines-global-strategy-for-diagnosis-management. html).

2. O'Donnell DE, LamMIU, Webb KA. Spirometric correlates of improvement in exercise performance after anticholinergic therapy in chronic obstructive pulmonary disease. Am J Respir Crit Care Med. 1999;160:542-549.

3. O'Donnell DE, Revill SM, Webb KA. Dynamic hyperinflation and exercise intolerance in chronic obstructive pulmonary disease. Am J Respir Crit Care Med. 2001;164:770-777.

4. Ferguson GT. Why does the lung hyperinflate? Proc Am Thorac Soc. 2006;3(2):176-179.

5. Garcia-Rio F, Lores V, Mediano O, et al. Daily physical activity in patients with chronic obstructive pulmonary disease is mainly associated with dynamic hyperinflation. Am J Respir Crit Care Med. 2009;180(6):506-512.

6. Belman MJ, Botnick WC, Shin JW. Inhaled bronchodilators reduce dynamic hyperinflation during exercise in patients with chronic obstructive pulmonary disease. Am J Respir Crit Care Med. 1996;153:967-975.

7. Wedzicha JA, Seemungal TA, MacCallum PK, et al. Acute exacerbations of chronic obstructive pulmonary disease are accompanied by elevations of plasma fibrinogen and serum IL-6 levels. Thromb Haemost. 2000;84(2):210-215.

International Journal of COPD

\section{Publish your work in this journal}

The International Journal of COPD is an international, peer-reviewed journal of therapeutics and pharmacology focusing on concise rapid reporting of clinical studies and reviews in COPD. Special focus is given to the pathophysiological processes underlying the disease, intervention programs, patient focused education, and self management protocols.
8. Donaldson GC, Seemungal TA, Bhowmik A, Wedzicha JA. Relationship between exacerbation frequency and lung function decline in chronic obstructive pulmonary disease. Thorax. 2002;57(10):847-852.

9. Soler-Cataluna JJ, Martinez-Garcia MA, Roman Sanchez P, Salcedo E, Navarro M, Ochando R. Severe acute exacerbations and mortality in patients with chronic obstructive pulmonary disease. Thorax. 2005; 60(11):925-931.

10. De Backer W, Devolder A, Poli G, et al. Lung deposition of BDP/ formoterol HFA pMDI in healthy volunteers, asthmatic, and COPD patients. J Aerosol Med Pulm Drug Deliv. 2010;23(3):137-148.

11. Quanjer PH, Tammeling GJ, Cotes JE, Pedersen OF, Peslin R, Yernault JC. Lung volumes and forced ventilatory flows. Report Working Party Standardization of Lung Function Tests, European Community for Steel and Coal. Official Statement of the European Respiratory Society. Eur Respir J Suppl. 1993;16:5-40.

12. Mahler DA, Weinberg DH, Wells CK, Feinstein AR. The measurement of dyspnea. Contents, interobserver agreement, and physiologic correlates of two new clinical indexes. Chest. 1984;85:751-758.

13. O'Donnel DE, Fluge T, Gerken F, et al. Effects of tiotropium on lung hyperinflation, dyspnoea and exercise tolerance in COPD. Eur Respir J. 2004;23:832-840.

14. Taube C, Lehnigk B, Paasch K, et al. Factor analysis of changes in dyspnea and lung function parameters after bronchodilation in chronic obstructive pulmonary disease. Am J Respir Crit Care Med. 2000;162:216-220.

15. Papi A, Paggiaro P, Nicolini G, Vignola AM, Fabbri LM. Beclomethasone/ formoterol vs fluticasone/salmeterol inhaled combination in moderate to severe asthma. Allergy. 2007;62:1182-1188.

16. Scichilone N, Battaglia S, Sorino C, et al. Effects of extra-fine inhaled beclomethasone/formoterol on both large and small airways in asthma. Allergy. 2010;65(7):897-902.

17. Calverley PM, Kuna P, Monsó E, et al. Beclomethasone/formoterol in the management of COPD: a randomised controlled trial. Respir Med. 2010;104(12):1858-1868.

18. Mahler DA, Witek TJ Jr. The MCID of the transition dyspnea index is a total score of one unit. COPD. 2005;2(1):99-103.

19. Papi A, Paggiaro PL, Nicolini G, Vignola AM, Fabbri LM. Beclomethasone/formoterol versus budesonide/formoterol combination therapy in asthma. Eur Respir J. 2007;29:682-689.

20. Huchon G, Magnussen H, Chuchalin A, Dymek L, Gonod FB, Bousquet J. Lung function and asthma control with beclomethasone and formoterol in a single inhaler. Respir Med. 2009;103:41-49.

21. Calverley PMA, Anderson JA, Celli B; for the TORCH Investigators. Salmeterol and fluticasone propionate and survival in chronic obstructive pulmonary disease. N Engl J Med. 2007;356(8):775-789.

22. Di Marco F, Milic-Emili J, Boveri B, et al. Effect of inhaled bronchodilators on inspiratory capacity and dyspnoea at rest in COPD. Eur Respir J. 2003;21:86-94.

23. Sturton RG, Trifilieff A, Nicholson AG, Barnes PJ. Pharmacological characterization of indacaterol, a novel once daily inhaled 2 adrenoceptor agonist, on small airways in human and rat precision-cut lung slices. J Pharmacol Exp Ther. 2008;324(1):270-275.

24. Italian Registry for Clinical Trials. http://ricerca-clinica.agenziafarmaco. it/en/node/22. Accessed September 10, 2011.

\section{Dovepress}

This journal is indexed on PubMed Central, MedLine and CAS. The manuscript management system is completely online and includes a very quick and fair peer-review system, which is all easy to use. Visit http://www.dovepress.com/testimonials.php to read real quotes from published authors. 